\title{
Burdur yöresi doğal Anadolu karaçamı meşceresinde sıklık bakımının üç yıllık sonuçları
}

\author{
Three-year results of precommercial thinning in Burdur region natural Anatolian black pine stand
}

\author{
Esra BAYAR ${ }^{\mathrm{D}}$, Ayşe DELigöz
}

Isparta Uygulamalı Bilimler Üniversitesi Orman Fakültesi Orman Mühendisliği Bölümü, Isparta Türkiye

\section{Eser Bilgisi/Article Info}

Araștırma makalesi / Research article DOI: $10.17474 /$ artvinofd.476662

Sorumlu yazar/Corresponding author Esra BAYAR

e-mail: esrabayar@isparta.edu.tr Geliş tarihi / Received

31.10.2018

Düzeltme tarihi / Received in revised form

21.01.2019

Elektronik erişim / Online available

31.01.2019

Anahtar kelimeler:

Büyüme

Sıklık bakımı

Aralık-mesafe

Artım

Anadolu karaçamı

Keywords:

Growth

Precommercial thinning

Spacing

Increment

Anatolian black pine

\begin{abstract}
Özet
Bu çalışmada, doğal Anadolu karaçamı [Pinus nigra Arn. subsp. pallasiana (Lamb.) Holmboe] meşceresinde farklı derecelerde uygulanan sıklık bakımının büyüme özellikleri üzerindeki etkisi araştırılmıştır. Sıklık bakımı işlemleri kontrol, 2-2.5X2-2.5 m ve 3-3.5X3-3.5 m aralık-mesafe olmak üzere rastlantı blokları deneme desenine göre üç yinelemeli olarak üç farklı düzeyde uygulanmıştır. Burdur Orman İşletme Müdürlüğü sınırları içerisinde yer alan araştırma alanına, 2015 yılı mart ayında sıklık bakımı işlemi uygulanarak üç yıl boyunca her gelişme dönemi sonunda büyüme özelliklerinden çap, boy ve tepe yarıçapı ölçülmüştür. Üç yılın sonunda sıklık bakımı işlemlerinin çap, boy, tek ağaçta göğüs yüzeyi ve tepe yarıçapı artımı üzerinde istatistiksel anlamda önemli etkisinin olduğu belirlenmiştir. Buna göre en yüksek çap ve tek ağaçta göğüs yüzeyi artımı sıklık bakımı 3-3.5 m aralıklarla uygulanan alanda belirlenirken, en yüksek boy artımı kontrol alanında tespit edilmiştir. Tepe yarıçapı artımı ise, üçüncü yılın sonunda kontrole kıyasla sıklık bakımı uygulanan alanlarda daha yüksek çıkmıştır. Sıkıı bakımının kısa dönemde büyüme özellikleri üzerindeki etkisi değerlendirildiğinde, boy hariç 3-3.5 m aralıklarla uygulanan sıklık bakımı müdahalesinin ağaçların gelişimi üzerinde olumlu etkisinin olduğu tespit edilmiştir. Fakat, yüksek kalite ve verim açısından karar verebilmek için uzun vadeli sonuçlara ve yeni araştırmalara ihtiyaç bulunmaktadır.
\end{abstract}

\begin{abstract}
In this study, the effects of the different levels of precommercial thinning (PCT) on growth parameters was investigated in natural Anatolian black pine [Pinus nigra Arn. subsp. pallasiana (Lamb.) Holmboe] stand. PCT was designed three different levels (control, 2-2.5 m and 3-3.5 m spacing) with three replicates in a randomised block design. The study area was located within the boundaries of Burdur Forest Management Directorate. PCT treatment was applied in March 2015 and diameter, height and crown radius were measured at the end of the each growing seasons for three years. At the end of three years, precommercial thinning was found to be statistically significant on diameter, height, individual tree basal area, and crown radius increment. According to this, while the highest diameter and individual tree basal area were determined in the PCT treatment with 3-3.5 m spacing, the highest height increment was found in the control plot. Crown radius increment was higher in the PCT treatment compared to the control plot at the end of three years. When effects of PCT on growth parameters in the short term was evaluated, it was determined that PCT treatments applied with 3-3.5 m spacing has a positive effect on the development of trees except the height increment. However, long-term results and new research were needed to make decisions in terms of high quality and yield.
\end{abstract}

\section{GiRiş}

Ülkemizde, yayılış alanı bakımından çok önemli bir yeri olan Anadolu karaçamı [Pinus nigra Arn. subsp. pallasiana (Lamb.) Holmboe], dona ve kuraklığa karşı dayanıklı olması ve odununun çok geniş kullanma yeri bulunması nedeniyle ülke ekonomisine büyük katkısı olan önemli bir orman ağacı türümüzdür. Odunu bu kadar önemli olan türün gençleştirme çağına ulaşıncaya kadar bakım tedbirlerinin yapılması odun kalitesi açısından oldukça önemlidir. Bakım çalışmaları, meşcerenin kuruluş evresinden gençleştirme evresine kadar geçen uzun bir süre içinde, amaca uygun olarak yapılan bütün işlemleri kapsar (Odabaşı vd. 2007). Bakım çalışmaları ile meşcere sıklı̆̆ının belirlenmesi, odun kalitesinin arttırılması ve ağaçların büyümesi bakımından önemli bir yere sahiptir (Mäkinen et al. 2006). Ülkemizde bakım müdahaleleri çok zaman alan ve pahalı olan çalışmalardır. Elde edilen ürünün ekonomik değeri ve kalifiye eleman yetersizliği gibi sebeplerden dolayı bu çalışmalar yeterince yerine getirilememektedir (Tüfekçioğlu 2006). Bu çalışmalar ihmal edilirse, gelişmelerinin en aktif çağlarında olan genç meşcerelerde ve bilhassa ışık ağaçlarında bozulmalar 
meydana gelmekte ve idare süresinin sonunda optimal kuruluşa ulaşamamaktadır. Stabiliteden uzak hale gelen meşcereler kar, fırtına ve çı̆̆ gibi tabiat olaylarından olumsuz etkilenmektedir (OGM 2012). Ancak zamanında, gereğince ve yeterince yapılacak olan meşcere bakımları ile kaliteli ve kalın çaplı meşcereler kurmak mümkün olabilir (Özçelik 2000).

Ülkemizde uygulanan bakım tedbirlerinden biri olan sıklık bakımı, sıklık çağında uygulanan bir bakım tedbiridir (Saatçioğlu 1971). Sıklık bakımlarında amaç, meşcereyi kendi haline bırakmayıp, planlı müdahalelerle yetişme ortamının ekolojik özellikleri ile türün/türlerin biyolojik özelliklerini ön planda tutan işletme amacına uygun bir gelişme sürecine sokmak ve böylece meşcere kalitesinin yükselmesi için gerekli önlemleri almaktır (Genç 2011). Biyolojik bir topluluk olan meşcerelerde tüm bakım tedbirleri gibi sıklık bakımları da zamanında ve uygun şiddette yapılmalıdır (Kaymakçı vd. 2000). Sıklık bakımlarının zamanında yapılmaması çap artımını yavaşlatmaktadır (Özdemir vd. 1987). Sıklık bakımlarının tek bir defada şiddetli yapılması durumunda ise, meşcere dış etkilere karşı dayanıksız hale gelebilmektedir (Özdemir vd. 1987; Özçelik 2013). Sıklık bakımları ile müdahaleler ılımlı sürdürülmelidir (Odabaşı vd. 2007). Müdahale şiddeti, meşceredeki genel hacim verimini mümkün olan en yüksek düzeyde tutacak şekilde ayarlanmalıdır. Dolayısıyla yapılacak müdahalelerin şiddeti isabetli tespit edilmelidir (Erkan vd. 2017).

Ülkemizde sayıları az olmakla birlikte Toros sediri (Cedrus libani A. Rich.), kızılçam (Pinus brutia Ten.), karaçam (Pinus nigra Arn.) sarıçam (Pinus sylvestris L.), kayın (Fagus orientalis Lipsky.) gibi türlerde sıklık bakımı çalışmaları yapılmıştır. Yapılan bu çalışmalarda sıklık bakımının çap üzerinde önemli derecede etkili olduğu, ancak boy büyümesi üzerinde etkili olmadığı (Özdemir vd. 1987; Umut vd. 1996; Eler vd. 2004; Özçelik ve Eler 2009; Yılmaz vd. 2010), çap ve göğüs yüzeyinde etkili olduğu (Öncül vd. 2016), göğüs yüzeyinde etkili olup, boyda etkili olmadığı (Umut vd. 1996; Kaymakçı vd. 2000), hem çap hem de boy üzerinde etkili olduğu (Sıvacıoğlu vd. 2006) belirtilmektedir. Ekonomik değeri olan Anadolu karaçamının daha düzgün, dolgun ve boylu gövde yapabilmesi için ideal sıklık bakımı müdahalesinin belirlenmesine ihtiyaç vardır. Bu çalışmanın amacı, ülkemiz odun ihtiyacının karşılanmasında önemli bir yere sahip olan Anadolu karaçamı meşcerelerinde farklı derecelerde uygulanan sıklık bakımı müdahalelerinin büyüme özellikleri üzerindeki etkisini araştırmaktır.

\section{MATERYAL ve YÖNTEM}

\section{Materyal}

Çalışmamıza konu edilen saha Anadolu karaçamının doğal yayılış gösterdiği Burdur Orman İşletme Müdürlüğü Çamoluk Orman İşletme Şefliği (Aziziye) sınırları içerisinde yer almaktadır. Deneme alanının yeri seçilirken, öncelikle sahaların doğal yolla gençleştirilerek sıklık çağına gelmiş olmasına, sahanın deneme deseninin sığabileceği büyüklükte meşcere özellikleri itibariyle homojen yapıda olmasına, herhangi bir hastalık veya zararlılara maruz kalmamış olmasına ve daha önce sıklık bakımı müdahalesinin yapılmamış olmasına dikkat edilmiştir. Deneme alanı, $37^{\circ} 24^{\prime}$ kuzey enlemi ile $30^{\circ} 11^{\prime}$ doğu boylamı arasında (Şekil 1), ortalama yükseltisi 1350 m, eğimi \%39, bakısı kuzey doğu, ortalama yaşı 19 ve meşcere tipi Çka $\mathrm{C}_{3}$ olan orman alanında bulunmaktadır. Burdur meteoroloji istasyonuna ait son 10 yıllık iklim verileri dikkate alındığında; deneme alanı Erinç yöntemine göre yarı-kurak iklim tipi kapsamında yer almaktadır.

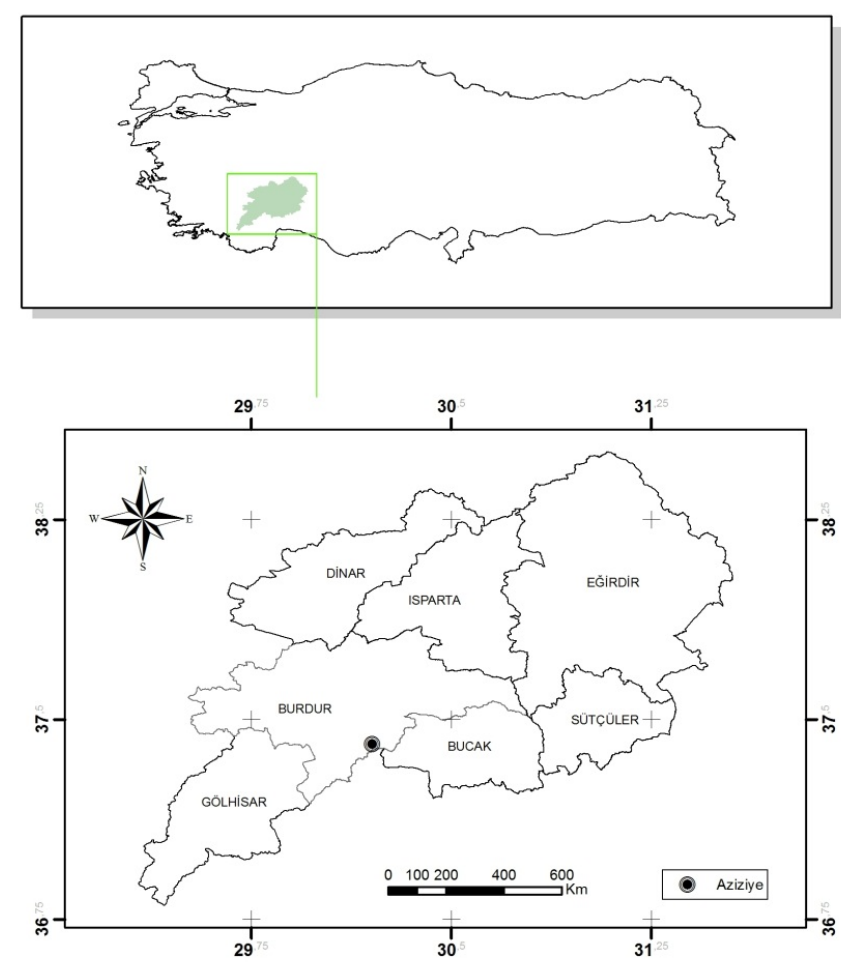

Şekil 1. Deneme alanının coğrafik konumu 


\section{Yöntem}

Sıklık bakımı işlemleri birisi kontrol olmak üzere üç farklı düzeyde (kontrol, 2-2.5X2-2.5 m ve 3-3.5X3-3.5 m aralıkmesafe bırakılarak) uygulanmıştır (Şekil 2). Sıklık bakımı işlemi 2015 yılı mart ayında uygulanmıştır. Her bir deneme alanında rastlantı blokları deneme desenine göre üç yinelemeli olarak 9 işlem parseli (3 sıklık bakımı işlemi x 3 tekerrür) alınmıştır. İşlem parselleri arasında tampon şerit bırakılmıştır. İşlem parsel büyüklükleri, sahadaki bireylerin yaş benzerliği ve sahadaki dağılımı itibariyle bireylerin mümkün olduğunca homojen olması dikkate alınarak 140 ile $200 \mathrm{~m}^{2}$ arasında değişmiştir. Sıklık bakımı müdahaleleri uygulanmadan önce, her bir işlem parselindeki tüm bireylerin göğüs çapı $\left(\mathrm{d}_{1.30 \mathrm{~m}}\right)$ ölçüm yeri yağlı boya ile halka şeklinde işaretlenmiş ve işaretli kısımdan göğüs çapı $\left(\mathrm{d}_{1.30 \mathrm{~m}}\right)$ ölçümleri yapılmıştır.
Örnek alanlar içindeki tüm ağaçların çap $\left(\mathrm{d}_{1.30 \mathrm{~m}}\right)$ ölçümleri yapıldıktan sonra sıklık bakımı müdahalelerine geçilmiştir. Sıklık bakımı müdahaleleri yapılırken alanda kalacak ağaçların çap, boy ve tepe tacı bakımından mümkün olduğunca benzer özellikte olmasına dikkat edilmiştir. Bunun için her bir işlem parselinde düzgün gövdeli, iyi şekillenmiş, çatallanmamış, tepesi kırılmamış veya zarar görmemiş, görünürde herhangi bir hastalık veya zararlı sorunu olmayan, sağlıklı, güçlü ve boylu ağaçların bırakılması tercih edilmiştir. Kontrol parsellerine hiçbir müdahale yapılmamıştır. Buna göre kontrol işleminde ortalama hektarda 6357 adet birey bulunurken, sıklık bakımı 2-2.5 m aralıklarla uygulanan alanda 2326 adet, 3-3.5 m aralıklarla uygulanan alanda ise 1202 adet birey bırakılmıştır.
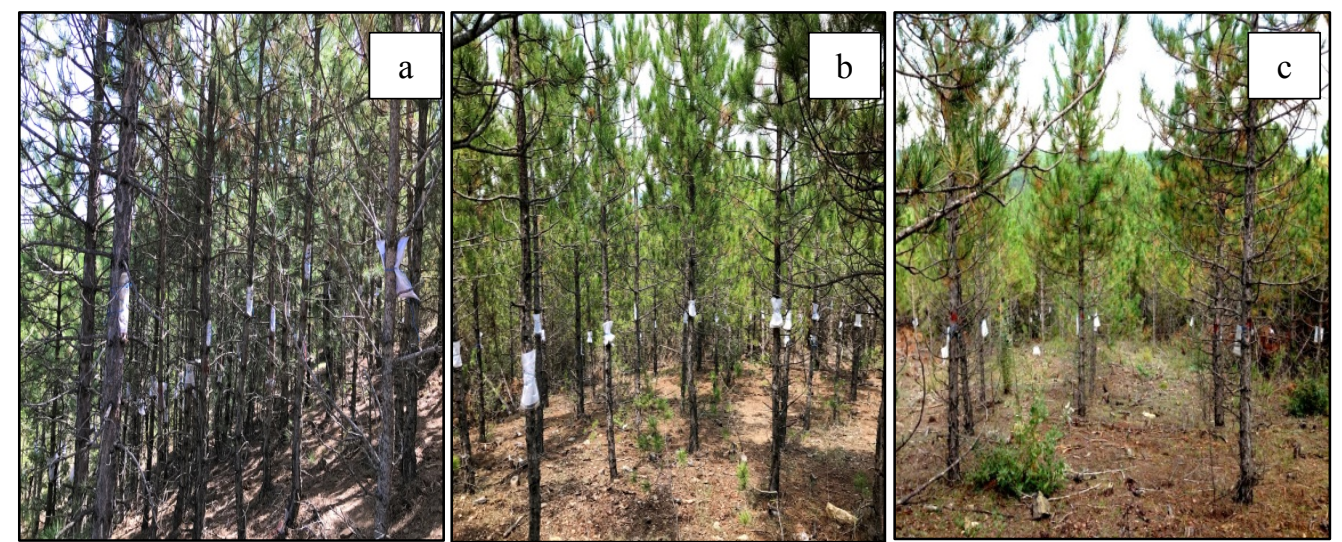

Şekil 2. Deneme alanında uygulanan sıklık bakımı işlemleri (a) Kontrol, (b) 2-2.5X2-2.5 m (c) 3-3.5X3-3.5 m

Deneme alanı kurulduktan hemen sonra ve 2015, 2016 ve 2017 yılları gelişme dönemi sonlarında ağaçların çap, boy ve tepe yarıçapları ölçülmüştür. Elde edilen veriler SPSS 20.0 Windows paket programında değerlendirilmiştir. İşlemler arasındaki farklılığı belirlemek amacıyla önce ANOVA testi uygulanmıştır. Bu analiz sonucunda başlangıçtaki çap, boy ve tepe yarıçapı değerleri farklılık göstermiştir. Bu yüzden başlangıçtaki farklılıklar dikkate alınarak ANCOVA (kovaryans) analizi uygulanmıştır. Bazı araştırmacılarda da büyüme parametrelerindeki başlangıç değerlerindeki farklılıklarından dolayı kovaryans testi uygulamıştır (Eler vd. 2004; Lindgren et al. 2007; Lindgren and Sullivan 2013). Kovaryans analizinden sonra sıklık bakımı işlemlerini karşılaştırmak için Bonferroni testi yapılmıştır. Varmola and Salminen (2004)'de işlemler arasındaki farklılı̆ı karşılaştırmak için Bonferroni testini uygulamıştır.

\section{BULGULAR}

Sıklık bakımı müdahalelerinin hemen ardından dönem başında yapılan çap ölçümlerinde, ortalama göğüs çapı kontrol işleminde $5.80 \mathrm{~cm}$ iken, sıklık bakımı 2-2.5 $\mathrm{m}$ ve 3-.35 m aralıklarla uygulanan işlemlerde sırasıyla $6.69 \mathrm{~cm}$ ve $6.74 \mathrm{~cm}$ olarak bulunmuştur. Üçüncü gelişme dönemi sonunda bu değerler sırasıyla $6.88 \mathrm{~cm}, 8.30 \mathrm{~cm}$ ve 8.67 $\mathrm{cm}$ olarak belirlenmiştir. Ortalama boy değerleri incelendiğinde, üçüncü gelişme dönemi sonunda bu değerler kontrol işleminde $5.45 \mathrm{~m}, 2-2.5 \mathrm{~m}$ aralıklarla uygulanan sıklık bakımı işleminde $5.00 \mathrm{~m}$ ve 3-3.5 m aralıklarla uygulanan sıklık bakımında ise $4.88 \mathrm{~m}$ olarak tespit edilmiştir (Çizelge 1). 
Çizelge 1. Sıklık bakımı işlemlerine ait ortalama göğüs çapı, boy, toplam göğüs yüzeyi ve boy/çap ${ }_{130} \mathrm{~m}$ oranı değerleri (Ortalama \pm Standart hata)

\begin{tabular}{|c|c|c|c|c|c|}
\hline Özellikler & İşlemler & 2015 yılı periyot başı & 2015 yılı periyot sonu & 2016 yılı periyot sonu & 2017 yılı periyot sonu \\
\hline \multirow[t]{3}{*}{ Göğüs çapı (cm) } & Kontrol & $5.80 \pm 0.15$ & $5.99 \pm 0.15$ & $6.50 \pm 0.16$ & $6.88 \pm 0.16$ \\
\hline & 2-2.5 m & $6.69 \pm 0.22$ & $7.15 \pm 0.21$ & $7.80 \pm 0.22$ & $8.30 \pm 0.22$ \\
\hline & 3-3.5 m & $6.74 \pm 0.24$ & $7.24 \pm 0.24$ & $8.08 \pm 0.24$ & $8.67 \pm 0.25$ \\
\hline \multirow[t]{3}{*}{ Boy $(m)$} & Kontrol & $4.54 \pm 0.11$ & $4.92 \pm 0.11$ & $5.19 \pm 0.13$ & $5.45 \pm 0.13$ \\
\hline & 2-2.5 m & $4.24 \pm 0.11$ & $4.66 \pm 0.11$ & $4.84 \pm 0.11$ & $5.00 \pm 0.11$ \\
\hline & 3-3.5 m & $4.22 \pm 0.10$ & $4.59 \pm 0.10$ & $4.72 \pm 0.11$ & $4.88 \pm 0.11$ \\
\hline \multirow[t]{3}{*}{ Toplam göğüs yüzeyi (m²/ha) } & Kontrol & $20.27 \pm 2.09$ & $21.61 \pm 2.36$ & $24.84 \pm 2.33$ & $27.53 \pm 2.39$ \\
\hline & $2-2.5 \mathrm{~m}$ & $8.30 \pm 1.66$ & $9.39 \pm 1.47$ & $11.14 \pm 1.51$ & $12.57 \pm 1.41$ \\
\hline & 3-3.5 m & $4.59 \pm 0.21$ & $5.23 \pm 0.04$ & $6.46 \pm 0.28$ & $7.39 \pm 0.31$ \\
\hline \multirow[t]{3}{*}{ Boy/Çap $1.30 \mathrm{~m}$} & Kontrol & $0.71 \pm 0.02$ & $0.74 \pm 0.02$ & $0.72 \pm 0.02$ & $0.72 \pm 0.02$ \\
\hline & $2-2.5 \mathrm{~m}$ & $0.74 \pm 0.03$ & $0.74 \pm 0.02$ & $0.68 \pm 0.02$ & $0.66 \pm 0.02$ \\
\hline & 3-3.5 m & $0.68 \pm 0.02$ & $0.68 \pm 0.02$ & $0.62 \pm 0.01$ & $0.59 \pm 0.01$ \\
\hline
\end{tabular}

Aziziye deneme alanında 2015 yılı periyot başında kontrol, 2-2.5 m ve 3-3.5 m aralık bırakılarak sıklık bakımı uygulanan alanlarda toplam göğüs yüzeyi sırasıyla, 20.27 $\mathrm{m}^{2} / \mathrm{ha}, 8.30 \mathrm{~m}^{2} /$ ha ve $4.59 \mathrm{~m}^{2} /$ ha iken, 2017 yılı periyot sonunda bu değerler $27.53 \mathrm{~m}^{2} / \mathrm{ha}, 12.57 \mathrm{~m}^{2} /$ ha ve 7.39 $\mathrm{m}^{2} /$ ha olarak tespit edilmiştir. Ortalama boy/çap $1.30 \mathrm{~m}$ oranı ise, üçüncü gelişme dönemi sonunda kontrol işleminde 0.72, sıklık bakımı 2-2.5 $\mathrm{m}$ aralıklarla uygulanan işlemde 0.66 ve 3-3.5 m aralıklarla uygulanan işlemde 0.59 'dur (Çizelge 1 ). Kovaryans analizi sonucuna göre, sıklık bakımı işlemlerinin üç gelişme döneminde de çap artımı ve tek ağaçta göğüs yüzeyi artımı üzerinde önemli $(P<0.001)$ bir etkisi bulunmaktadır. Ortalama boy artımı irdelendiğinde, 2016 ve 2017 yıllarında anlamlı farklılıklar belirlenmiştir (Çizelge 2).

Bonferroni testi sonucuna göre birinci gelişme dönemi sonunda çap ve tek ağaç göğüs yüzeyi artımına göre 2$2.5 \mathrm{~m}$ ve 3-3.5 $\mathrm{m}$ aralık bırakılarak uygulanan sıklık bakımı işlemleri arasındaki ortalama farkı istatistiksel anlamda önemli değilken, kontrol ile 2-2.5 m ve 3-3.5 m aralıklarla uygulanan sıklık bakımı işlemleri arasındaki ortalama farkı önemli bulunmuştur. Üçüncü yılın sonunda en fazla göğüs çapı ve tek ağaç göğüs yüzeyi artımı sırasıyla sıklık bakımı 3-3.5 m ve 2-2.5 m aralıklarla uygulanan işlemlerde tespit edilirken, en düşük göğüs çapı ve tek ağaç göğüs yüzeyi artımı kontrol işleminde belirlenmiştir (Çizelge 3). Bonferroni testi sonuçlarına göre boy artımı değerleri incelendiğinde, birinci gelişme dönemi sonunda işlemler arasında ortalama boy artımı arasındaki fark istatistiksel anlamda önemli bulunmazken, ikinci gelişme dönemi sonunda 3-3.5 m aralıklarla uygulanan sıklık bakımı ve kontrol işlemleri arasında ve üçüncü gelişme dönemi sonunda kontrol ile 2-2.5 $\mathrm{m}$ ve 3-3.5 $\mathrm{m}$ aralık bırakılarak uygulanan sıklık bakımı işlemleri arasında bu fark önemli bulunmuştur. Sıklık bakımı uygulanan alanlarda ortalama boy artımı arasındaki fark önemsiz bulunmuştur. Bu bağlamda kontrol alanı sıklık bakımı uygulanan alanlara kıyasla daha fazla ortalama boy artımına sahiptir (Çizelge 3).

Çizelge 2. Sıklık bakımının ortalama göğüs çapı, boy ve tek ağaçta göğüs yüzeyi artımı üzerindeki etkisi (Ortalama \pm Standart hata)

\begin{tabular}{|c|c|c|c|c|}
\hline Özellikler & İşlemler & 2015-2015 & 2015-2016 & 2015-2017 \\
\hline \multirow[t]{4}{*}{ Göğüs çapı (cm) } & Kontrol & $0.19 \pm 0.02$ & $0.71 \pm 0.02$ & $1.01 \pm 0.03$ \\
\hline & $2-2.5 m$ & $0.46 \pm 0.03$ & $1.10 \pm 0.04$ & $1.59 \pm 0.05$ \\
\hline & 3-3.5 m & $0.50 \pm 0.04$ & $1.33 \pm 0.05$ & $1.91 \pm 0.06$ \\
\hline & F değeri & $44.979 * *$ & $80.578^{* *}$ & $84.097^{* *}$ \\
\hline \multirow[t]{4}{*}{ Boy (m) } & Kontrol & $0.39 \pm 0.03$ & $0.65 \pm 0.04$ & $0.91 \pm 0.04$ \\
\hline & 2-2.5 m & $0.42 \pm 0.03$ & $0.60 \pm 0.04$ & $0.76 \pm 0.04$ \\
\hline & 3-3.5 m & $0.37 \pm 0.03$ & $0.51 \pm 0.04$ & $0.67 \pm 0.04$ \\
\hline & F değeri & 0.516 & $3.669 *$ & $7.933^{* *}$ \\
\hline Tek ağaç & Kontrol & $2.17 \pm 0.20$ & $7.60 \pm 0.32$ & $12.11 \pm 0.41$ \\
\hline \multirow{3}{*}{ yüzeyi $\left(\mathrm{cm}^{2}\right)$} & 2-2.5 m & $4.61 \pm 0.33$ & $12.04 \pm 0.52$ & $18.11 \pm 0.68$ \\
\hline & 3-3.5 m & $5.22 \pm 0.41$ & $15.16 \pm 0.64$ & $22.62 \pm 0.84$ \\
\hline & F değeri & $34.113^{* *}$ & $67.568^{* *}$ & $75.393^{* *}$ \\
\hline
\end{tabular}


Çizelge 3. Sıklık bakımı işlemlerinin göğüs çapı, boy ve tek ağaçta göğüs yüzeyi artımına göre Bonferroni testi sonuçları

\begin{tabular}{|c|c|c|c|c|c|c|c|c|}
\hline \multirow[t]{2}{*}{ Yıl } & \multicolumn{2}{|c|}{ İşlemler } & \multicolumn{2}{|c|}{ Göğüs çapı (cm) } & \multicolumn{2}{|l|}{ Boy (m) } & \multicolumn{2}{|c|}{ Tek ağaç göğüs yüzeyi $\left(\mathrm{cm}^{2}\right)$} \\
\hline & & & Ortalamalar farkı & St. Hata & Ortalamalar farkı & St. Hata & Ortalamalar farkı & St. Hata \\
\hline \multirow[t]{3}{*}{2015} & Kontrol & $2-2.5 \mathrm{~m}$ & $-0.264^{* *}$ & 0.035 & -0.031 & 0.045 & $-2.441^{* *}$ & 0.389 \\
\hline & $2-2.5 \mathrm{~m}$ & 3-3.5 m & -0.038 & 0.047 & 0.044 & 0.045 & -0.617 & 0.525 \\
\hline & 3-3.5 m & Kontrol & $0.302^{* *}$ & 0.041 & -0.014 & 0.045 & $3.058^{* *}$ & 0.457 \\
\hline \multirow[t]{3}{*}{2016} & Kontrol & $2-2.5 \mathrm{~m}$ & $-0.393^{* *}$ & 0.047 & 0.051 & 0.050 & $-4.437^{* *}$ & 0.611 \\
\hline & $2-2.5 \mathrm{~m}$ & 3-3.5 m & $-0.230^{* *}$ & 0.063 & 0.084 & 0.050 & $-3.120^{* *}$ & 0.825 \\
\hline & 3-3.5 m & Kontrol & $0.624^{* *}$ & 0.055 & $-0.135^{*}$ & 0.051 & $7.557^{* *}$ & 0.717 \\
\hline \multirow[t]{3}{*}{2017} & Kontrol & $2-2.5 \mathrm{~m}$ & $-0.501^{* *}$ & 0.060 & $0.151^{*}$ & 0.060 & $-6.006^{* *}$ & 0.799 \\
\hline & $2-2.5 \mathrm{~m}$ & 3-3.5 m & $-0.315^{* *}$ & 0.080 & 0.087 & 0.059 & $-4.511^{* *}$ & 1.079 \\
\hline & 3-3.5 m & Kontrol & $0.816^{* *}$ & 0.070 & $-0.238^{* *}$ & 0.060 & $10.517^{* *}$ & 0.938 \\
\hline
\end{tabular}

*işlemler arasında \%5 önem düzeyinde anlamlı farklııı olduğunu ifade etmektedir.

**işlemler arasında \%1 önem düzeyinde anlamlı farklılık olduğunu ifade etmektedir.

Tepe yarıçapı değerleri incelendiğinde, üçüncü yıl sonunda (2017 yılı) kontrol alanında ortalama tepe yarıçapı genişliği kuzey, güney, doğu ve batı yönünde sırasıyla, 1.34 m, 1.35 m, 1.35 m ve 1.24 m iken, 3-3.5 m aralık bırakılarak uygulanan sıklık bakımı alanında 1.62 m, $1.74 \mathrm{~m}, 1.72 \mathrm{~m}$ ve $1.53 \mathrm{~m}$ olarak belirlenmiştir (Çizelge 4). Kovaryans analizi sonucuna göre, tepe yarıçapı artım miktarı 2015 yılında doğu yönünde, 2016 ve 2017 yılında tüm yönlerde işlemler arasında önemli $(P<0.01) \quad$ olduğu tespit edilmiştir (Çizelge 5).

Çizelge 4. Sıklık bakımı işlemlerine ait dört yöndeki ortalama tepe yarıçapı değerleri (Ortalama₫Standart hata)

\begin{tabular}{|c|c|c|c|c|c|}
\hline Tepe yarıçapı (m) & İşlemler & 2015 yılı periyot başı & 2015 yılı periyot sonu & 2016 yılı periyot sonu & 2017 yılı periyot sonu \\
\hline \multirow[t]{3}{*}{ Kuzey } & Kontrol & $0.89 \pm 0.03$ & $1.05 \pm 0.05$ & $1.21 \pm 0.04$ & $1.34 \pm 0.04$ \\
\hline & $2-2.5 \mathrm{~m}$ & $0.89 \pm 0.03$ & $1.10 \pm 0.04$ & $1.28 \pm 0.04$ & $1.52 \pm 0.04$ \\
\hline & 3-3.5 m & $0.88 \pm 0.04$ & $1.10 \pm 0.04$ & $1.37 \pm 0.04$ & $1.62 \pm 0.04$ \\
\hline \multirow[t]{3}{*}{ Güney } & Kontrol & $0.82 \pm 0.03$ & $1.03 \pm 0.04$ & $1.21 \pm 0.04$ & $1.35 \pm 0.04$ \\
\hline & $2-2.5 \mathrm{~m}$ & $0.82 \pm 0.04$ & $1.07 \pm 0.04$ & $1.31 \pm 0.04$ & $1.57 \pm 0.05$ \\
\hline & 3-3.5 m & $0.71 \pm 0.04$ & $1.02 \pm 0.05$ & $1.36 \pm 0.05$ & $1.74 \pm 0.06$ \\
\hline \multirow[t]{3}{*}{ Doğu } & Kontrol & $0.82 \pm 0.04$ & $0.99 \pm 0.05$ & $1.18 \pm 0.04$ & $1.35 \pm 0.05$ \\
\hline & $2-2.5 \mathrm{~m}$ & $0.84 \pm 0.03$ & $1.07 \pm 0.04$ & $1.26 \pm 0.04$ & $1.57 \pm 0.04$ \\
\hline & 3-3.5 m & $0.80 \pm 0.04$ & $1.14 \pm 0.05$ & $1.41 \pm 0.04$ & $1.72 \pm 0.05$ \\
\hline \multirow[t]{3}{*}{ Batı } & Kontrol & $0.77 \pm 0.03$ & $0.92 \pm 0.04$ & $1.12 \pm 0.03$ & $1.24 \pm 0.03$ \\
\hline & $2-2.5 \mathrm{~m}$ & $0.71 \pm 0.03$ & $0.92 \pm 0.03$ & $1.12 \pm 0.04$ & $1.42 \pm 0.04$ \\
\hline & 3-3.5 m & $0.68 \pm 0.04$ & $0.91 \pm 0.04$ & $1.21 \pm 0.05$ & $1.53 \pm 0.05$ \\
\hline
\end{tabular}

Çizelge 5. Sıklık bakımının dört yöndeki tepe yarıçapı artımı üzerindeki etkisi (Ortalama \pm Standart hata)

\begin{tabular}{|c|c|c|c|c|}
\hline Tepe yarıçapı (m) & İşlemler & 2015-2015 & 2015-2016 & 2015-2017 \\
\hline \multirow[t]{4}{*}{ Kuzey } & Kontrol & $0.16 \pm 0.03$ & $0.32 \pm 0.03$ & $0.45 \pm 0.03$ \\
\hline & 2-2.5 m & $0.21 \pm 0.03$ & $0.39 \pm 0.03$ & $0.63 \pm 0.03$ \\
\hline & 3-3.5 m & $0.22 \pm 0.03$ & $0.49 \pm 0.03$ & $0.74 \pm 0.03$ \\
\hline & $F$ değeri & 1.690 & $6.158^{* *}$ & $17.994 * *$ \\
\hline \multirow[t]{4}{*}{ Güney } & Kontrol & $0.21 \pm 0.03$ & $0.40 \pm 0.04$ & $0.54 \pm 0.04$ \\
\hline & 2-2.5 m & $0.25 \pm 0.03$ & $0.50 \pm 0.04$ & $0.76 v 0.04$ \\
\hline & $3-3.5 \mathrm{~m}$ & $0.30 \pm 0.03$ & $0.63 \pm 0.04$ & $1.01 \pm 0.05$ \\
\hline & $F$ değeri & 2.046 & $9.723 * *$ & $27.998^{* *}$ \\
\hline \multirow[t]{4}{*}{ Doğu } & Kontrol & $0.17 \pm 0.03$ & $0.36 \pm 0.03$ & $0.53 \pm 0.04$ \\
\hline & 2-2.5 m & $0.23 \pm 0.03$ & $0.42 \pm 0.03$ & $0.73 \pm 0.04$ \\
\hline & 3-3.5 m & $0.33 \pm 0.03$ & $0.60 \pm 0.03$ & $0.91 \pm 0.04$ \\
\hline & $F$ değeri & $8.601 * *$ & $13.830 * *$ & $21.726 * *$ \\
\hline \multirow[t]{4}{*}{ Batı } & Kontrol & $0.16 \pm 0.03$ & $0.36 \pm 0.03$ & $0.48 \pm 0.03$ \\
\hline & 2-2.5 m & $0.21 \pm 0.03$ & $0.41 \pm 0.03$ & $0.71 \pm 0.03$ \\
\hline & 3-3.5 m & $0.23 \pm 0.03$ & $0.52 \pm 0.03$ & $0.84 \pm 0.03$ \\
\hline & $F$ değeri & 1.785 & $6.510 * *$ & $27.045^{* *}$ \\
\hline
\end{tabular}

**işlemler arasında \%1 önem düzeyinde anlamlı farklılık olduğunu ifade etmektedir.
Bonferroni testi sonucuna göre üçüncü yılın sonunda kuzey yönünde tepe yarıçapı artımına göre ortalamalar farkı incelendiğinde sıklık bakımı işlemleri arasında önemli bir farklılık belirlenmezken, kontrol ile $2-2.5 \mathrm{~m}$ ve 3-3.5 $\mathrm{m}$ aralık bırakılarak uygulanan sıklık bakımı arasında anlamlı farklılık tespit edilmiştir. Sıklık bakımı uygulanan alanlar, kontrole kıyasla kuzey yönünde daha fazla tepe tacı artımına sahiptir. Güney, doğu ve batı yönündeki tepe yarıçapı artım değerleri incelendiğinde, üçüncü yılın sonunda kontrole kıyasla sıklık bakımı uygulanan alanların daha fazla tepe yarıçapı artımına sahip olduğu belirlenmiştir (Çizelge 6; Çizelge 7). 
Çizelge 6. Sıklık bakımı işlemlerinin kuzey ve güney yöndeki tepe yarıçapı artımına göre Bonferroni testi sonuçları

\begin{tabular}{|c|c|c|c|c|c|c|}
\hline \multirow[t]{2}{*}{ YII } & \multirow[t]{2}{*}{ İşlemler } & & \multicolumn{2}{|c|}{ Kuzey (m) } & \multicolumn{2}{|c|}{ Güney (m) } \\
\hline & & & Ortalamalar farkı & St. Hata & Ortalamalar farkı & St. Hata \\
\hline \multirow[t]{3}{*}{2015} & Kontrol & 2-2.5 m & -0.052 & 0.036 & -0.044 & .044 \\
\hline & 2-2.5 m & 3-3.5 m & -0.009 & 0.036 & -0.046 & .045 \\
\hline & 3-3.5 m & Kontrol & 0.061 & 0.036 & 0.091 & .045 \\
\hline \multirow[t]{3}{*}{2016} & Kontrol & 2-2.5 m & -0.065 & 0.047 & -0.101 & .052 \\
\hline & 2-2.5 m & 3-3.5 m & -0.098 & 0.047 & $-0.133^{*}$ & .053 \\
\hline & 3-3.5 m & Kontrol & $0.163^{* *}$ & 0.047 & $0.233^{* *}$ & .053 \\
\hline \multirow[t]{3}{*}{2017} & Kontrol & 2-2.5 m & $-0.173^{* *}$ & 0.048 & $-0.225^{* *}$ & .063 \\
\hline & 2-2.5 m & 3-3.5 m & -0.113 & 0.048 & $-0.252^{* *}$ & .064 \\
\hline & 3-3.5 m & Kontrol & $0.287^{* *}$ & 0.048 & $0.477^{* *}$ & .064 \\
\hline
\end{tabular}

Çizelge 7. Sıklık bakımı işlemlerinin doğu ve batı tepe yarıçapı artımına göre Bonferroni testi sonuçları

\begin{tabular}{|c|c|c|c|c|c|c|}
\hline \multirow[t]{2}{*}{ Yıl } & \multirow[t]{2}{*}{ İşlemler } & & \multicolumn{2}{|c|}{ Doğu (m) } & \multicolumn{2}{|c|}{ Batı (m) } \\
\hline & & & Ortalamalar farkı & St. Hata & Ortalamalar farkı & St. Hata \\
\hline \multirow[t]{3}{*}{2015} & Kontrol & $2-2.5 m$ & -.065 & .041 & -.051 & .036 \\
\hline & $2-2.5 m$ & 3-3.5 m & $-.102^{*}$ & .041 & -.015 & .036 \\
\hline & 3-3.5 m & Kontrol & $.167^{* *}$ & .041 & .066 & .037 \\
\hline \multirow[t]{3}{*}{2016} & Kontrol & $2-2.5 m$ & -.063 & .048 & -.043 & .043 \\
\hline & 2-2.5 m & 3-3.5 m & $-.180^{* *}$ & .048 & $-.109^{*}$ & .043 \\
\hline & 3-3.5 m & Kontrol & $.243^{* *}$ & .048 & $.152^{* *}$ & .044 \\
\hline \multirow[t]{3}{*}{2017} & Kontrol & 2-2.5 m & $-.207^{* *}$ & .058 & $-.226^{* *}$ & .048 \\
\hline & 2-2.5 m & 3-3.5 m & $-.174^{* *}$ & .058 & $-.125^{*}$ & .048 \\
\hline & 3-3.5 m & Kontrol & $.381^{* *}$ & .058 & $.351^{* *}$ & .048 \\
\hline
\end{tabular}

*işslemler arasında \%5 önem düzeyinde anlamlı farklılık olduğunu ifade etmektedir.

**işlemler arasında \%1 önem düzeyinde anlamlı farklılık olduğunu ifade etmektedir.

\section{TARTIŞMA ve SONUÇ}

Bakım çalışmalarından biri olan sıklık bakımı, meşcere kurmanın ilk basamağıdır (Özdemir vd. 1987). Sıklık bakımı çalışmaları ağaçların çap gelişimini önemli derecede etkilemektedir (Pothier 2002; Huuskonen and Hynynen 2006). Sıklık bakımında müdahale şiddetinin artmasıyla ağaçların çapı da artmaktadır (Pettersson 1993; Ruha and Varmola 1997; Varmola and Salminen 2004; Simard et al. 2004; Weiskittel et al. 2009). Çalışmamızda 2016 ve 2017 yılı sonunda en düşük ortalama göğüs çapı artımı kontrol alanlarında belirlenirken, en yüksek ortalama göğüs çapı artımı 3.5X3-3.5 m aralık-mesafe bırakılarak uygulanan sıklık bakımı işleminde belirlenmiştir. Sıklık bakımı 2-2.5X2-2.5 $\mathrm{m}$ aralık mesafeyle uygulanan işlem iki işlemin arasında kalmıştır. Sıklık bakımı müdahale şiddeti arttıkça ortalama göğüs çapı artımı artmaktadır. Toros sedirinde yapılan sıklık bakımı (kontrol, mutedil ve kuvvetli müdahale) çalışması sonucunda da, sıklık bakımının kalan ağaçların göğüs çapı büyümesine olumlu etkilerinin olduğu tespit edilmiştir (Yılmaz vd., 2010). Bakım müdahalelerinin çap ve boy gelişimi üzerindeki etkisinin incelendiği 12 yaşındaki doğal Toros sediri meşceresinde birisi kontrol olmak üzere dört farklı (kontrol, klasik, 1.5 $\mathrm{m} \times 1.5 \mathrm{~m}$ ve $1.5 \mathrm{~m} \times 3 \mathrm{~m}$ aralık-mesafe) sıklık bakımı işleminin etkileri 3 yıl boyunca gözlemlenmiştir. Çalışma sonucunda $1.5 \mathrm{~m} \times 3 \mathrm{~m}$ aralık-mesafe bırakılarak yapılan işlemin tek ağaçta en fazla çap artımına neden olduğu, boy büyümesi üzerinde ise işlemlerin herhangi bir etkisinin bulunmadığı tespit edilmiştir (Eler vd. 2004). Daha birçok çalışmada da meşcere sıklığındaki azalışa bağlı olarak çap artımının yükseldiği belirtilmiştir (Ceylan 1986; Özdemir vd. 1987; Eler ve Keskin 1989; Umut vd. 1996; Eler vd. 2004; Simard et al. 2004; Makineci 2005; Sivacıoğlu vd. 2006; Huuskonen and Hynynen 2006; Río et al. 2008; Özçelik ve Eler 2009; Çiçek vd., 2010; Saygılı Kayhan 2011; Yılmaz vd. 2010; Öncül vd. 2016).

Sıklık bakımı müdahaleleri ile çap artımındaki artışın temel nedeni ağaç sayısının azaltılmasına bağlı olarak mevcut kaynakların daha az sayıdaki birey tarafından kullanmasıdır. Yani alanda kalan bireylerin daha fazla ışık, su ve besin maddesinden yararlanması ve dolayısıyla da fotosentezindeki artıştır (Goudiaby et al. 2011). Topraktaki su miktarının ağaçlardaki çap artımı üzerinde etkisi bulunmaktadır. Ağaçların gelişimi çevre faktörlerine kıyasla daha çok suyun etkisi altındadır 
(Çepel 1995). Makineci (2005)'nin çalışmasında da aralama yapılan alanlarda toprak neminin artması ve daha az sayıdaki bireyin daha geniş bir toprak hacminden yararlanma imkânı bulması ve dolayısıyla da kök rekabetinin azalması sonucu çap gelişimin arttığı vurgulanmıştır.

Çalışmamızda sıklık bakımının ortalama boy artımı üzerindeki etkileri incelendiğinde, sıklık bakımı müdahaleleri 2016 ve 2017 yıllarında ortalama boy artımı üzerinde istatistiksel anlamda önemli bulunmuştur. 2016 yılında kontrol ile 3-3.5 m aralıklarla uygulanan sıklık bakımı arasında önemli bir farklıık belirlenmiştir. 2017 yılında ise en yüksek ortalama boy artımı kontrol işleminde belirlenirken, sıklık bakımı uygulanan işlemler arasında anlamlı bir farklılık tespit edilmemiştir. Ruha ve Varmola (1997)'nın çalışmasında, çok geniş aralıklarla uygulanan sıklık bakımında boy artımının azaldığı ve ışık rekabeti azalması nedeniyle ağaç büyümesinin dallara yöneldiği bildirilmiştir. Anadolu karaçamında yapılan gecikilmiş sıklık bakımı çalışmasında, sıklık bakımı müdahalelerin boy büyümesi üzerinde etkili olmadığı tespit edilmiştir (Kaymakçı vd. 2000). Pinus contorta var. latifolia meşceresinde uygulanan sıklık bakımı işlemlerinin uzun dönem etkileri incelendiğinde, 15 yıllık boy artımı üzerinde sıklık bakımı yoğunluğunun herhangi bir etkiye sahip olmadığı tespit edilmiştir (Lindgren ve Sullivan 2013). Bazı araştırmalara göre, sıklık bakımı şiddeti boy artımı üzerinde etkili değildir ama çap artımına bağlı olarak artmaktadır (Özdemir vd. 1987; Eler vd. 2004; Özçelik ve Eler 2009; Yılmaz vd. 2010; Ferguson et al. 2011; Prévost and Gauthier 2012). Eler (1990), Toros sediri meşceresinde uyguladığı silvikültürel işlemlerin (kontrol, mutedil, kuvvetli) meşcere orta boyu üzerinde anlamlı etkisinin olduğunu ve en fazla boy büyümesinin kuvvetli aralama işleminde tespit edildiğini belirtmiştir. Yine Sıvacıoğlu vd. (2006), sıklık bakımı uygulanan alanlarda ortalama meşcere boyunun kontrol alanlarına kıyasla daha fazla olduğunu belirtmiştir.

Meşcere dayanıklılığı için boy/çap $1.30 \mathrm{~m}$ oranı kullanılmaktadır. Bu oran ne kadar büyük olursa, ağaç ve ağaç topluluklarının dayanıklılığı o kadar düşük olmaktadır (Yılmaz vd. 2010). Yüksek boy/çap oranı zayıf, kuvvetsiz ağaçları gösterir. Bu oran ağaçların kar ve rüzgar zararına karşı hassaslığını belirler. Yoğunluğun bir fonksiyonu olması nedeniyle rekabetin göstergesi olarak boy/çap oranı kullanılabilir. Pinus ponderosa var. ponderosa meşceresinde uygulanan sıklık bakımlarında bireyler arasındaki mesafe arttıkça boy/çap ${ }_{1.30} \mathrm{~m}$ oranı azalmıştır (Ferguson et al. 2011). Çalışmamızda üç yılın sonunda boy/çap oranı kontrol işleminde 0.72, 3-3.5 m aralıklarla uygulanan sıklık bakımı işleminde 0.59 olarak belirlenmiştir. Dolayısıyla kontrol işleminin boy/çap $1.30 \mathrm{~m}$ oranı sıklık bakımı uygulanan işlemlere kıyasla daha yüksek olduğundan, daha fazla zayıf ağaçları barındırdığı söylenebilir. Benzer sonuç sıklık bakımı uygulanan Toros sediri türünde de bulunmuştur. Kontrol alanının ortalama boy/çap $1.30 \mathrm{~m}$ oranı, müdahale alanlarına kıyasla daha yüksek bulunmuştur (Yılmaz vd. 2010). Yüksek boy/çap $1.30 \mathrm{~m}$ oranına sahip olan meşcere, düşük boy/çap ${ }_{1.30} \mathrm{~m}$ oranına sahip meşcereye göre abiyotik faktörlere karşı daha hassasdır ve daha fazla zarara uğramaktadır (Vallinger ve Fridman 1997).

Bir meşcerenin yetiştirme gücünün en güvenilir göstergelerinden biri göğüs yüzeyidir (Özdemir vd. 1987; Kaymakçı vd. 2000). Çalışmamızda üçüncü gelişme dönemi (2017 yılı) sonunda kontrol alanına kıyasla en fazla göğüs yüzeyi artımı 3-3.5 m aralıklarla uygulanan sıklık bakımında tespit edilmiştir. Toplam göğüs yüzeyi miktarı ise, 2017 yılında kontrol işleminde $27.53 \mathrm{~m}^{2} / \mathrm{ha}$, 2-2.5X2-2.5 m aralık-mesafeyle uygulanan sıklık bakımı işleminde $12.57 \mathrm{~m}^{2} /$ ha ve 3-3.5X3-3.5 m aralık-mesafeyle uygulanan işlemde $7.39 \mathrm{~m}^{2} /$ ha olmuştur. Kızılçamda yapılan sıklık bakımında ise hiçbir müdahale görmeyen kontrol parselinde toplam göğüs yüzeyi yüksek bulunmuştur (Özdemir vd. 1987). Çalışmamızda 3-3.5 m aralıklarla uygulanan sıklık bakımı müdahalelerinde toplam göğüs yüzeyi miktarı düşüktür. Nitekim şiddetli sıklık bakımlarının önemli şekilde hasılat kaybı ile sonuçlandığı belirtilmektedir (Huuskonen ve Hynynen 2006). Aşırı şiddette yapılan aralama çalışmaları ile meşcereden çıkarılan ağaçların neden olduğu boşluklar, kalan ağaçlar tarafından tam olarak kullanılamayabilir ve üretim kayıpları oluşabilir (Erkan vd. 2017). Deneme alanında sıklık bakımının üçüncü yılında toplam göğüs yüzeyi kontrol alanlarının toplam göğüs yüzeyi miktarına ulaşmamıştır. Gördes işletmesinde Anadolu karaçamı 
meşceresinde yapılan sıklık bakımı çalışmasında, sıklık bakımı uygulanan alanların beşinci yılın sonunda ulaştıkları göğüs yüzeyinin müdahale yapılmayan alanların göğüs yüzeyine ulaşamadığı belirlenmiştir (Kaymakçı vd. 2000). Benzer bulgular Toros sediri meşcerelerinde uygulanan sıklık bakımı çalışmasında da elde edilmiştir. Hektardaki mevcut meşcere göğüs yüzeyi mutedil ve şiddetli müdahale işlem parsellerinde, artan sıklık bakımı yoğunluğu ile azalmıştır. 10 yıl sonunda meşcere göğüs yüzeyi, her iki sıklık bakımı işleminde kontrol işleminden daha düşük kalmıştır (Yılmaz vd. 2010). Bununla birlikte sıklık bakımları sonunda göğüs yüzeyinde bir azalma meydana gelmiş olsa bile, ileriki yıllarda daha fazla çap artımı olması nedeniyle göğüs yüzeyi, kontrole kıyasla sıkık bakımı uygulanan alanlarda daha fazla olmaktadır. Müdahale sonunda toplam göğüs yüzeyindeki azalmanın artan çap artımı ile kapatıldığı belirtilmiştir (Sıvacıoğlu vd. 2006).

Bir ağacın dal özelliği hem genetik hem de çevresel faktörlerden etkilenir. Dal açısı veya boğum başına dal sayısı üzerinde sıklık bakımı işlemlerinin önemli bir etkisi belirlenmemiş olmasına rağmen, dal çapı üzerinde hem sıklık bakımı sonrası meşcere sıklığı hem de sıklık bakımının yapıldığı dönemdeki boy önemli derecede etkilidir (Ulvcrona et al. 2007). Çalışmamızda 2017 yılı sonunda ağacın tüm yönlerinde kontrol alanlarına kıyasla sıklık bakımı uygulanan alanlar daha fazla tepe yarıçapı artımına sahiptir. Genellikle müdahale şiddeti arttıkça tepe yarıçapı artımı artmıştır. Daha geniş bırakılan aralıklar tepe oranının artmasına ve tepenin uzamasına neden olur. Çünkü alt dallar dar aralık-mesafe uygulanan alandaki gibi geniş aralık-mesafe uygulanan alanlarda hemen ölmezler (Ferguson et al. 2011). Şiddetli ayıklama kesimleri ile ağaçlar büyüme enerjisini yan dal sürgünlerinin gelişmesi için kullanmaktadır (Tolunay 2003). Picea rubens Sarg. ve Abies balsamea L. Mill. meşceresinde $2.4 \times 2.4 \mathrm{~m}$ aralık-mesafe ile uygulanan sıklık bakımı işlemini takiben 25. yılında yapılan ölçümlerde, sıklık bakımının tek ağaç göğüs çapı, tepe oranı ve tepe genişliğini kontrole göre önemli şekilde arttırdığı tespit edilmiştir (Weiskittel et al. 2009). Çalışmamızda sıklık bakımı yapılan alanlarda tepe yarıçapı gelişimi daha iyi olmasına rağmen, sıklık bakımları ile başlangıçta oluşturulan boşlukların üçüncü yıl sonunda 2-2.5 $\mathrm{m}$ aralık bırakılarak uygulanan sıklık bakımı alanlarında nispeten kapanmak üzere olduğu, 3$3.5 \mathrm{~m}$ aralıklarla sıklık bakımı uygulanan alanlarda ise oluşan büyük boşlukların kapanmadığı gözlemlenmiştir. Kayın meşceresinde de mutedil müdahalelere göre daha iyi bir gelişim gösteren kuvvetli sıklık müdahalelerinde meşcere içinde oluşan büyük boşlukların sıklık bakımının üçüncü yılında kapanmadığı belirtilmiştir. Mutedil sıklık müdahalesi uygulanan alanlarda kalan ağaçlar ise dördüncü yıl sonunda boşlukları kapatmıştır (Yücesan vd. 2015).

Sonuç olarak, kontrol alanlarına göre sıklık bakımı alanlarındaki ağaçların çap ve göğüs yüzeyi artımları yükselmiştir. Fakat burada sıklık bakımı müdahale şiddetine karar verirken sadece çap artımlarındaki artışı dikkate almak doğru olmayabilir. Her ne kadar müdahale şiddeti arttıkça çap ve göğüs yüzeyi artımı yükselmiş olsa da, 3-3.5 m aralıklarla uygulanan sıklık bakımı işleminde toplam göğüs yüzeyi oldukça düşüktür. 3-3.5 m aralıklarla uygulanan sıklık bakımı müdahalesine karar verebilmek için uzun vadeli sonuçlara ve yeni araştırmalara ihtiyacımız bulunmaktadır. İleriki yıllarda daha fazla çap ve göğüs yüzeyi artımı nedeniyle 3-3.5 m aralıklarla sıklık bakımı yapılan alanlardaki toplam göğüs yüzeyinin kontrol alanlarına yaklaşması veya geçmesi durumunda karar vermek veya bir değerlendirme yapmak daha doğru olacaktır. Çünkü, göğüs yüzeyi oldukça düşürülen 3-3.5 m aralıklarla uygulanan sıklık bakımı işleminde alanda kalan bireyler alanın gerçek potansiyeli olan verimi kendi üzerinde toparlayarak, alınması gereken hasılatı sağlayamayabilir. Ayrıca, 3-3.5 $\mathrm{m}$ aralık bırakılarak uygulanan sıkık bakımları sonucunda, başlangıçta oluşan boşlukların üçüncü yıl sonunda kapanmadığı dikkate alındığında tepe tacı genişliğinin daha da büyüyerek dal çaplarının da artması söz konusu olabilir. Mümkün olduğunca düzgün, dolgun, dalsız ve budaksız gövde odunu temini açısından bu hususlarında dikkate alınması gerekmektedir. Dolayısıyla sıklık bakımı müdahalesinin odun kalitesi üzerindeki etkisi konusunda yeni araştırmalara ihtiyacımız bulunmaktadır. Uygulamada mevcut olanakları yeterince kullanabilecek sayıda birey sahada bırakılarak artım ve kalite kayıplarına neden olunmaması ve yeterli göğüs yüzeyine ulaşılabilmesi bakımından, çalışmamızda 
meşcere kapalııı̆ını kademeli olarak düşürmenin daha iyi olacağı düşünülerek, 2-2.5X2-2.5 m aralık-mesafe bırakılarak sıklık bakımlarının uygulanması önerilebilir.

\section{TEŞEKKÜR}

Bu çalışma Süleyman Demirel Üniversitesi Fen Bilimleri Enstitüsü'nde hazırlanmış olan doktora tezinin bir kısmıdır ve TÜBITAK TOVAG 1140659 nolu proje tarafından finansal olarak desteklenmiştir. Finansal desteğinden dolayı TÜBiTAK'a ve arazi çalışmalarına destek veren Burdur Orman İşletme Müdürlüğü Çamoluk Orman Işletme Şefliğine ve personeline teşekkür ederiz.

\section{KAYNAKLAR}

Ceylan B (1986) Muğla yöresindeki genç kızılçam (Pinus brutia Ten.) meşcerelerinde ilk aralama müdahaleleri üzerine silvikültürel araştırmalar. Ormancılık Araştırma Enstitüsü Teknik Bülten No:196, Ankara.

Çepel N (1985) Toprak fiziği. İstanbul Üniversitesi Orman Fakültesi Yayınları, İstanbul.

Çiçek E, Yılmaz F, Özbayram AK, Çetin B (2010) Aralamanın dişbudak (Fraxinus angustifolia ssp. oxycarpa) plantasyonunun gelişimine etkisi. III. Ulusal Karadeniz Ormancılık Kongresi. 20-22 Mayıs 2010, Artvin, s.886-894.

Eler Ü (1990) Antalya yöresinde doğal sedir (Cedrus libani A. Rich.) meşcerelerinde gecikmiş aralama kesimlerinin gelişme üzerine etkileri. Ormancılık Araştırma Enstitüsü Yayınları Teknik Bülten No:44, Ankara.

Eler Ü, Keskin S (1989) Antalya yöresi kızılçam (Pinus brutia Ten.) ağaçlandırma alanlarında gecikmiş ilk aralamalarda uygulanacak silvikültürel işlemin gelişme üzerine etkileri. Ormancılık Araştırma Enstitüsü Yayınları Teknik Bülten No:36-39, Antalya.

Eler Ü, Özçelik R, Özdemir İ, Çatal Y (2004) Göller yöresinde iki genç doğal toros sediri (Cedrus libani A. Rich.) meşceresinde gecikilmiş sıklık bakımının gelişme üzerine etkileri. Süleyman Demirel Üniversitesi Fen Bilimleri Enstitüsü Dergisi 8(1): 1-6.

Erkan N, Aydın AC, Eler Ü (2017) Güney-Batı Anadolu bölgesindeki kızılçam (Pinus brutia Ten.) kültür ormanlarında değişik silvikültürel uygulamalara göre artım ve büyüme ilişkileri. Ormancılık Araştırma Dergisi 4(2):90-99.

Ferguson DE, Byrne JC, Wykoff WR, Kummet B, Hensold T (2011) Response of ponderosa pine stands to pre-commercial thinning on nez perce and spokane tribal forests in the Inland Northwest, USA. U.S. Department of Agriculture, Forest Service, Rocky Mountain Research Station.

Genç M (2011) Orman bakımı. Süleyman Demirel Üniversitesi Orman Fakültesi Yayını, Isparta.

Goudiaby V, Brais S, Grenier Y, Berninger F (2011). Thinning effects on jack pine and black spruce photosynthesis in easternboreal forests of Canada. Siva Fennica 45(4): 595-609.
Huuskonen S, Hynymen J (2006) Timing and intensity of precommercial thinning and their on the first commercial thinning in scots pine stands. Silva Fennica 40(4):645-662.

Kaymakçı E, Erkuloğlu ÖS, Eronat AF (2000) Gördes işletmesinde karaçam (Pinus nigra Arnold.)'da gecikilmiş sıklık bakımı üzerine araştırmalar. Orman Bakanlığı Ege Ormancılık Araştırma Enstitüsü Müdürlüğü, İzmir.

Lindgren PMF, Sullivan, TP (2013) Long-term responses of tree and stand growth of young lodgepole pine to pre-commercial thinning and repeated fertilization. Forest Ecology and Management 307:155-164.

Lindgren PMF, Sullivan TP, Sullivan DS, Brockley RP, Winter R (2007) Growth response of young lodgepole pine to thinning and repeated fertilization treatments: 10 -year results. Forestry 80(5):587-611.

Makineci E (2005) Sapsız meşe (Quercus petraea (Matlusch) Lieb.) baltalık ormanında aralamaların çap artımı ve bazı toprak özelliklerine etkileri. Süleyman Demirel Üniversitesi Orman Fakültesi Dergisi A(2):1- 10.

Mäkinen H, Isomäkı A, Hongiısto T (2006) Effect of half systematic and systematic thinning on the increment of scots pine and norway spruce in Finland. Forestry 79(1):103-121.

Odabaşı T, Çalışkan A, Bozkuş HF (2007) Orman bakımı. İstanbul Üniversitesi Orman Fakültesi Yayını, İstanbul.

OGM (2012) Genç meşcereler bakım seferberliği eylem planı 20122016. Orman ve Su İşleri Bakanlığı Orman Genel Müdürlüğü, Ankara.

Öncül Ö, Uğurlu Ç, Köse M, Tilki F (2016) Sıklık bakımının doğal sarıçam (Pinus sylvestris L.) meşcerelerinde çap ve göğüs yüzeyi üzerine etkisi. Ormancılık Araştırma Dergisi 1(3):29-37.

Özçelik R (2000) Meşcere bakımlarının büyümeye etkileri ve kızılçam örneği. Süleyman Demirel Üniversitesi Orman Fakültesi Dergisi 1:41-56.

Özçelik R, Eler Ü (2009) Effects of release cutting on the development of young natural Lebanon cedar (Cedrus libani A. Rich) stands of Western Mediterranean region of Turkey. Journal of Environmental Biology 30 (2):179-182.

Özçelik S (2013) Trabzon-Düzköy yöresi yapay kayın (Fagus orientalis Lipsky) sıklıklarında meşcere kuruluşu ve artım-büyüme ilişkisinin analizi. Yüksek Lisans Tezi, Karadeniz Teknik Üniversitesi Fen Bilimleri Enstitüsü, Trabzon.

Özdemir T, Eler Ü, Şırlak U (1987) Antalya bölgesi doğal kızılçam (Pinus brutia Ten.) ormanlarında ayıklama kesimleri (sıklık bakımı) ve etkileri üzerine araştırmalar. Ormancılık Araştırma Enstitüsü. Teknik Bülten No: 184.

Pettersson N (1993) The effect of density after precommercial thinning on volume and structure in Pinus Sylvestris and Picea Abies stands. Scandinavian Journal of Forest Research 8:1-4.

Pothier D (2002) Twenty-year results of precommercial thinning in a balsam fir stand. Forest Ecology and Management 168:177-186.

Prévost M, Gauthier MM (2012) Precommercial thinning increases growth of overstory aspen and understory balsam fir in a boreal mixedwood stand. Forest Ecology and Management 278:17-26. 
Río MD, Calama R, Cañellas I, Roig S, Montero G (2008) Thinning intensity and growth response in SW-European scots pine stands. Annals of Forest Science 65 (3):308-317.

Ruha T, Varmola M (1997) Precommercial thinning in naturally regenerated scots pine stands in northern Finland. Silva Fennica 31(4):401-415.

Saatçioğlu F (1971). Orman bakımı. İstanbul Üniversitesi Orman Fakültesi Yayını. No: 1636/160, İstanbul.

Saygılı Kayhan E (2011) Hopa Cankurtaran mevkii kayın meşcerelerinde farklı aralama derecelerinin büyüme ve biyokütle üzerine etkileri. Yüksek Lisans Tezi, Artvin Çoruh Üniversitesi Fen Bilimleri Enstitüsü, Artvin.

Sıvacıoğlu A, Durkaya A, Vurdu H, Benli R (2006) Taşköprü (Kastamonu) yöresi doğal sarıçam (Pinus sylvestris L.) meşcerelerinde sıklık bakımlarının artım ve büyümeye etkisi. Gazi Üniversitesi Orman Fakültesi Dergisi 6(2):153-166.

Simard SW, Blenner-Hassett T, Cameron IR (2004) Pre-commercial thinning effects on growth, yield and mortality in even-aged paper birch stands in Biritish Columbia. Forest Ecology and Management 190:163-178.

Tolunay D (2003) Aladağ'da (Bolu) sıklık çağındaki sarıçam (Pinus sylvestris L.) meşcerelerinde bakımların madde dolaşımına etkileri. İstanbul Üniversitesi Orman Fakültesi Dergisi 53(1):47-73.

Tüfekçioğlu U (2006) Ülkemiz ormancılığında bakım çalışmalarının önemi ve sorunları. Orman Mühendisliği Dergisi 7-8-9:24-26.

Ulvcrona KA, Claesson S, Sahlen K, Lundmark T (2007) The effects of timing of the pre-commercial thinning and stand density on stem form and branch characteristics of Pinus sylvestris. Forestry 80(3):323-335.

Umut B, Dündar M, Çelik O (1996) Sırıklık çağındaki kayın (Fagus orientalis Lipsky.) meşcerelerinin bakımı üzerine araştırmalar. İç Anadolu Ormancılık Araştırma Enstitüsü Yayınları. Teknik Bülten No:274, Ankara.

Vallinger E, Fridman J (1997) Modelling probability of snow and wind damage in scots pine stands using tree characteristics. Forest Ecology and Management 93(3):215-222.

Varmola M, Salminen H (2004) Timing and intensity of precommercial thinning in Pinus sylvestris stands. Scandinavian Journal of Forest Research 19:142-151.

Weiskittel AR, Kenefic LS, Seymour RS, Phillips LM (2009) Long-term effects of precommercial thinning on the stem dimensions, form and branch characteristics of red spruce and balsam fir crop trees in Maine, USA. Silva Fennica 43(3):397-409.

Yılmaz E, Çalışkan A, Alptekin Ü, Tüfekçi S, Aytar F, Keleş H, Yıldızbakan A (2010) Toros (Lübnan) sediri (Cedrus libani A. Rich.) sıklık çağı meşcerelerindeki bakım tedbirlerinin belirlenmesi, Ankara: Çevre ve Orman Bakanlığı Doğu Akdeniz Ormancılık Araştırma Enstitüsü, No:36, Tarsus.

Yücesan Z, Özçelik S, Oktan E (2015) Effects of thinning on stand structure and tree stability in an afforested oriental beech (Fagus orientalis Lipsky) stand in Northeast Turkey. Journal of Forestry Research 36(5):1075-1082. 